\title{
Predicting the Capability of Carboxylated Cellulose Nanowhiskers for the Remediation of Copper from Wastewater Effluent Using Statistical Approach
}

\author{
Hazren A. Hamid ${ }^{1, *}$, Hasnida Harun ${ }^{1}$, Norshuhaila Mohamed Sunar ${ }^{1}$, Faridahanim Ahmad ${ }^{1}$, \\ Nuramidah Hamidon ${ }^{1}$, Mimi Suliza Muhamad ${ }^{1}$, Latifah Jasmani ${ }^{2}$, Norhidayah Suleiman ${ }^{3}$ \\ ${ }^{1}$ Department of Civil Engineering Technology, Universiti Tun Hussein Onn Malaysia, Malaysia \\ ${ }^{2}$ Forest Products Division, Forest Research Institute Malaysia, Malaysia \\ ${ }^{3}$ Department of Food Technology, Universiti Putra Malaysia, Malaysia
}

Received August 2, 2019; Revised October 1, 2019; Accepted December 15, 2019

Copyright $\bigcirc 2019$ by authors, all rights reserved. Authors agree that this article remains permanently open access under the terms of the Creative Commons Attribution License 4.0 International License

\begin{abstract}
This study focused on remediation of spiked $\mathrm{Cu}(\mathrm{II})$ from wastewater effluent obtained from a real wastewater treatment plants (WWTPs) using oxidised cellulose nanowhisker (CNW) adsorbents. Response surface methodology (RSM) and artificial neural network (ANN) were used to develop an approach for the remediation of spiked $\mathrm{Cu}$ (II) from wastewater effluent. As remediation processes from wastewater are often complicated due to the variation in wastewater compositions, results obtained from the benchmark experiments are included as one of the independent variables for ANN modelling. This novel approach and the outcomes are allowed for the first time, since most studies do not consider matrix variability and its impact when evaluating the efficiency of an adsorbent. Moreover, to confirm the model suitability, additional 10 unseen experiments, which were not used in developing both models, were chosen to represent the system of conditions both inside and outside the system. This study found that the ANN model accounting for wastewater variability was superior to the RSM model and to the ANN model not including wastewater variability, in terms of the coefficient of determination $\left(\mathrm{R}^{2}\right)$, the absolute average deviation (AAD) and root mean squared error (RMSE) when predicting the efficiency of $\mathrm{Cu}(\mathrm{II})$ removal from the wastewater matrix.
\end{abstract}

Keywords Artificial Neural Networks, Adsorption, $\mathrm{Cu}$ (II) ions, Cellulose Nanowhiskers, Response Surface Methodology

\section{Introduction}

Adsorption is a complex process, as it involves the interaction of various parameters. Moreover, the complexity and variability of the wastewater matrix also have a direct impact on the process performance $[1,2]$. In addition, studies tend to focus on evaluating one single parameter at a time, which assumes each parameter operates independently. This is non-practical because parameter interactions cannot be elucidated using this approach [3].

Developing a new mathematical modelling for remediation process not only can reduce cost and time in wastewater treatment, but also investigate the effects of input variables or factors on an output variable or response. The capabilities of these models were applied to the case study: remediation of copper from water matrices using modified cellulose nanowhisker (CNW) adsorbents. In this study, the central composite design (CCD) was selected because as it has been extensively applied in adsorption studies $[4,5]$. The mathematical models, response surface methodology (RSM), and artificial neural network (ANN) are among the most popular models used in research on remediation of heavy metals from the clean water matrix $[6$, 7].

Copper is a naturally occurring element which is found in water, air, and soil, and is considered as one of the most dangerous substances found in the environment [8]. The maximum guideline concentration limit for copper discharge to water has been established by the Water Framework Directive of water policy discharge to inland surface water directive (2000/60/EC) [9]. With these strict guidelines for the regulated levels of copper for wastewater discharge $(1-28 \mu \mathrm{g} / \mathrm{L})$, proper and suitable treatment is 
required in order to meet these discharge limits.

Cellulose has been identified as a promising adsorbent for the remediation of heavy metals from the water matrix $[10,11]$. Although CNWs have been recognised due to their high surface area and high reactive group density on the surface, only limited research has been published on using CNWs as an adsorbent, as the majority of the literature has mainly focused on macroscopic lignocellulosic biomass such as jute, orange peel, and sugarcane bagasse fibres, rather than pure cellulose [12, 13]. In recent years, TEMPO (2,2,6,6-tetramethylpyperidine-1-oxyl)-mediated

oxidation has frequently been used to introduce carboxyl functional groups on the surface of nanowhiskers or native cellulose without affecting the crystallinity or changing the original fibrous morphology [14].

However, most of the previous literature focuses on ad-sorption studies by using either RSM or ANN, without comparing the performances between these two models. Furthermore, the testing of both RSM and ANN using new sets of experiments not belonging to the training data set has only been undertaken by a limited number of studies on biomass adsorption, and without consideration of how the additional experiments represent the system and provide a more accurate indicator of performance $[4,15]$. Moreover, studying the effect of matrix complexity and the variability of the wastewater, along with applying realistic conditions for WWTP, could lead to the establishment of a good knowledge based on adsorption behaviour and provide the foundation for further studies.

\section{Materials and Methods}

\subsection{Preparation of CNWs}

CNWs were produced from bleached cotton by hydrolysis with a mass fraction of $64 \%$ sulphuric acid to produce a suspension of highly crystalline CNWs according to standard procedures [16]. The resulting CNWs were then reacted with TEMPO, sodium bromide, and sodium hypochlorite for $45 \mathrm{~min}$ under constant stirring at room temperature $\left(\mathrm{T}=19^{\circ} \mathrm{C}\right)$ at $\mathrm{pH} 10$ to introduce the carboxyl groups onto the CNWs' surface followed by freeze-drying [17]. The characteristics and analyses of CNWs are crucial in understanding the mechanism on the adsorbent surface. The methods that have been used in this study are Fourier Transform Infra-Red (FTIR) spectroscopy, zeta potential, BrunauerEmmett-Teller (BET) method, scanning electron microscopy (SEM), transmission electron microscopy (TEM) and conductometric titration method.

\subsection{Wastewater Samples}

The sample collection was carried out at the Severn
Trent Water Stoke Bardolph WWTP in Nottingham, UK. Wastewater effluent was collected twice a week using a grab-sampling approach. Dissolved oxygen (DO) and temperature were measured by a DO meter (Jenway 970, Staffordshire, UK) and thermocouple thermometer (Digi-Sense, Cole-Parmer Instrument Ltd., UK), respectively at the sampling point to avoid any changes during storage.

\subsubsection{Wastewater Characteristics}

In order to perform a physico-chemical characterisation of the water samples, the American Public Health Association's Standard methods for the examination of water and wastewater were applied [18]. In each of the samples, the following water quality parameters: total suspended solids (TSS), $\mathrm{pH}$, conductivity, total dissolved solids (TDS) and chemical oxygen demand (COD) were determined.

\subsubsection{Wastewater Effluent Spiked with $\mathrm{Cu}(\mathrm{II})$}

The $\mathrm{Cu}(\mathrm{II})$ concentration in wastewater effluent was adjusted to the required concentrations $(1-5 \mathrm{mg} / \mathrm{L})$ by dissolving the appropriate amount of $\mathrm{CuSO}_{4} .5 \mathrm{H}_{2} \mathrm{O}$ in a $200 \mathrm{ml}$ volumetric flask, followed by dilution up to the mark by the addition of filtered effluent. The effluent was previously filtered through a standard $1.2 \mu \mathrm{m}$ glass fibre filter.

\subsection{Determination of the $\mathrm{Cu}(\mathrm{II})$ in the Solutions}

The initial and final concentration of $\mathrm{Cu}(\mathrm{II})$ in the wastewater effluent was determined by flame atomic absorption spectrometry (AAS) (Model No: 272, PerkinElmer Inc., USA). The hollow cathode lamp was operated at $10 \mathrm{~mA}$ and the analytical wavelength was set at $324.8 \mathrm{~nm}$. The standard solutions $(2-10 \mathrm{mg} / \mathrm{L})$ that span the working ranges were prepared by using the provided $1000 \mathrm{mg} / \mathrm{L}$ reference standard solution (ROMIL Ltd) for $\mathrm{Cu}(\mathrm{II})$ with Milli-Q water. A linear regression curve $(y=0.03313 x+0.00212)$ was obtained in the $\mathrm{Cu}(\mathrm{II})$ concentration ranging from 2 to $10 \mathrm{mg} / \mathrm{L}$ with a correlation coefficient of 0.999 .

\subsection{Batch Adsorption Studies Using Wastewater Effluent}

Batch experiments were performed in $100 \mathrm{~mL}$ conical flasks, in an incubator (Model No: 120, LMS Ltd., Kent, $\mathrm{UK})$, with temperature control and agitation $(150 \mathrm{rpm})$ using a mini table shaker (IKA Vibrax VXR, Germany). The contact time $(30 \mathrm{~min})$, and the temperature $\left(20^{\circ} \mathrm{C}\right)$ were selected on the basis of the results obtained from scoping experiments. The required weight of sorbent $(0.5-$ $10.0 \mathrm{~g} / \mathrm{L}$ ) was measured separately into the $100 \mathrm{~mL}$ conical flask, and then $20 \mathrm{~mL}$ of $\mathrm{Cu}(\mathrm{II})$ solution with the known concentration $(1-5 \mathrm{mg} / \mathrm{L})$ was added into the 
flasks. The initial and final solutions were separated by filtration using $0.2 \mu \mathrm{m}$ surfactant-free cellulose acetate membrane syringe filter and $\mathrm{Cu}(\mathrm{II})$ concentration determined using AAS.

The percentage of the removal $\mathrm{Cu}$ (II) ions by the sorbent and the adsorption capacity ( $\mathrm{mg} \mathrm{Cu}(\mathrm{II}) / \mathrm{g}$ ) was expressed by:

$$
\begin{gathered}
\text { \% removal }=\frac{\mathrm{C}_{\mathrm{o}}-\mathrm{C}_{\mathrm{e}}}{\mathrm{C}_{\mathrm{o}}} \times 100 \\
q_{e}=\left(\frac{\left(\mathrm{C}_{\mathrm{o}}-\mathrm{C}_{\mathrm{e}}\right) \mathrm{V}}{\mathrm{W}}\right)
\end{gathered}
$$

where $\mathrm{Co}(\mathrm{mg} / \mathrm{L})$ is the initial $\mathrm{Cu}(\mathrm{II})$ concentration and $\mathrm{C}_{\mathrm{e}}$ $(\mathrm{mg} / \mathrm{L})$ is the equilibrium $\mathrm{Cu}$ (II) concentration in solution, $\mathrm{V}$ is the volume of the solution (L), and $\mathrm{W}$ is the mass of adsorbent (g) [19].

\subsection{Benchmarks Study}

A benchmark study was performed in order to understand the complexity and variability of the wastewater matrix on the adsorption performance. For benchmark studies, $20 \mathrm{ml}$ of $4 \mathrm{mg} / \mathrm{L} \mathrm{Cu}(\mathrm{II})$ wastewater effluent spiked with $\mathrm{Cu}(\mathrm{II})$ was agitated with $1 \mathrm{~g} / \mathrm{L}$ sorbent dosage for 30 minutes at $20 \mathrm{C}$ at $\mathrm{pH}$ 6. This benchmark experiment was performed for each wastewater sample (for every sampling trip). The initial and final samples were separated by filtration using a 0.2 $\mu \mathrm{m}$ surfactant-free cellulose acetate membrane syringe and the concentration of the samples was determined by AAS.

\subsection{Prediction Model of $\mathrm{Cu}$ (II) Removal from the Wastewater Matrix}

\subsubsection{Response Surface Methodology (RSM)}

The RSM is an approach that combines mathematical and statistical techniques and can be applied to give a better overall understanding with a minimal number of experiments. The experimental data were processed using MINITAB 16 Statistical Software. The predicted percentage of the removal $\mathrm{Cu}$ (II) ions is explained by the following quadratic equation:

$$
\mathrm{Y}(\%)=\beta_{0}+\sum_{\mathrm{i}=1}^{\mathrm{k}} \beta_{\mathrm{i}} \mathrm{x}_{\mathrm{i}}+\sum_{\mathrm{i}=1}^{\mathrm{k}} \beta_{\mathrm{ii}} \mathrm{x}_{\mathrm{i}}^{2}+\sum_{\mathrm{i}<\mathrm{j}} \sum \beta_{\mathrm{ij}} \mathrm{x}_{\mathrm{i}} \mathrm{x}_{\mathrm{j}}+\varepsilon
$$

Where $\mathrm{Y}$ is the predicted response, $\mathrm{xi}$ and $\mathrm{xj}$ are the input variables, $\beta \mathrm{o}$ is the intercept term, $\beta \mathrm{i}$ is the coefficient of linear effect, $\beta \mathrm{ii}$ is the coefficient of squared effect, $\beta \mathrm{ij}$ is the coefficient of interaction effect and $\varepsilon$ is the random error.

\subsubsection{Artificial Neural Network}

An ANN is a powerful tool and has been widely used to model the effect of parameters influencing adsorption processes [5]. This network consists of three or more layers of neurons as the three-layer models with one hidden layer and is commonly applied when predicting the performance of many processes $[20,21]$. In order to use the ANN model for predicting $\mathrm{Cu}(\mathrm{II})$ removal from the water matrix, a feed-forward backpropagation was used for modelling the experimental design. In this study, the first layers of neurons representing the independent variables were identical to the factors considered in the RSM approach. Similar to the RSM modelling, the percentage removal of $\mathrm{Cu}$ (II) was considered as the output neurons and was developed in MATLAB (R2009b), Mathwork Inc. Software.

\subsection{Data Analysis and Statistical Techniques}

\subsubsection{Model Evaluation}

The regression analysis, graphical analysis, and analysis of variance (ANOVA) were undertaken using MINITAB 16 Statistical Software. The performance of the ANN and RSM model was statistically evaluated in terms of the coefficient of determination (R2), absolute average deviation (AAD), and the root mean squared error (RMSE). Both models and the parameters variation were determined based on the minimum value of the RMSE and $\mathrm{AAD}$ of the training and prediction set (Equation 4 and 5) [22].

$$
\begin{aligned}
\operatorname{RMSE} & \left.=\left(\frac{1}{\mathrm{n}} \sum_{\mathrm{i}=1}^{\mathrm{n}}\left(\mathrm{y}_{\mathrm{p}}-\mathrm{y}_{\mathrm{e}}\right)^{2}\right)\right)^{1 / 2} \\
A A D & =\left(\frac{1}{n} \sum_{i=1}^{n}\left(\frac{y_{p}-y_{e}}{y_{e}}\right)\right) \times 100
\end{aligned}
$$

Where $\mathrm{n}$ is the number of points, $\mathrm{y}_{\mathrm{p}}$ is the predicted value, $\mathrm{y}_{\mathrm{e}}$ is the experimental value.

\subsubsection{Test and Validation of the Model}

For purposes of validation and evaluation of RSM and ANN models, additional unseen experiments were conducted in addition to those determined by the CCD, consisting of combinations of experimental parameters not found in the training data set for the models. The prediction abilities of the newly constructed ANN and RSM models were also statistically measured in terms of $\mathrm{R}^{2}, \mathrm{AAD}$ and RMSE.

\section{Results and Discussion}

\subsection{Characteristics of CNW Adsorbents}

FTIR analysis demonstrated that the CNWs were successfully modified, with the appearance of a $\mathrm{C}=\mathrm{O}$ stretching band at $1740 \mathrm{~cm}^{-1}$, indicating the carboxyl content. The zeta potential of this oxidised CNW in water was $-74.4 \mathrm{mV}$, indicated the formation of a stable suspension. The BET method showed that the surface areas of un-modified CNW and oxidised CNW adsorbents were $15.72 \mathrm{~m}^{2} / \mathrm{g}$ and $43.11 \mathrm{~m}^{2} / \mathrm{g}$ respectively, within the 
reported range of surface area for CNWs. TEM was used to identify individual whiskers, which enabled the determination of their size and shape. The whiskers were measured to be $134.4 \pm 51.2 \mathrm{~nm}$ and $9.0 \pm 2.3 \mathrm{~nm}$ in length and width respectively. TEM images confirmed that the oxidised CNW maintain their initial morphological integrity after the oxidation process.

\subsection{Benchmarking the Wastewater Matrix from the Pollutant and Adsorbent Perspective}

New wastewater quality parameter (benchmark study) has been developed to quantify the impact of wastewater composition on the efficiency of $\mathrm{Cu}$ (II) removal by oxidised CNW adsorbents. The issue with previous studies is the assumption that the actual wastewater composition is the same for each experiment, or has no influence on the removal capability of that process. No work to date has performed benchmark experiments on each fresh wastewater sample to challenge that assumption.

The results showed that the percentage $\mathrm{Cu}$ (II) removal by oxidised $\mathrm{CNW}$ adsorbents varies for each wastewater sample on different sampling dates. Results over 6 weeks give an average $77.35 \% \pm 4.15$. This demonstrates that the complexity of wastewater, in terms of its composition and variability, affects the capability of the adsorbent to remediate $\mathrm{Cu}(\mathrm{II})$ from the wastewater matrix. Moreover, the complexity and variation of wastewater composition may also affect the accuracy and efficiency of mathematical modelling in predicting the capability of this adsorbent to remediate spiked copper from the wastewater effluent.

\subsection{Mathematical Modelling of Spiked Cu(II) Removal from Wastewater Effluent}

\subsubsection{Central Composite Design (CCD)}

The $\mathrm{pH}$, sorbent dosage, and initial concentration of wastewater effluent spiked with $\mathrm{Cu}(\mathrm{II})$ were used as independent (input) variables and were studied for their impact on the removal of spiked $\mathrm{Cu}$ (II) from wastewater effluent. The range of independent variables, with the levels of the experimental factors, is given in Table 1. The final equation in terms of coded factors obtained by the application of RSM is given by:

$$
\begin{gathered}
\mathrm{Z}(\%)=81.4753+1.5759 \mathrm{Y}_{1}+4.1651 \mathrm{Y}_{2}+ \\
7.1588 \mathrm{Y}_{3}+0.9451 \mathrm{Y}_{1}^{2}-2.3417 \mathrm{Y}_{2}^{2}-2.3848 \mathrm{Y}_{3}^{2}- \\
0.3212 \mathrm{Y}_{1} \mathrm{Y}_{2}-0.3087 \mathrm{Y}_{1} \mathrm{Y}_{2}-1.2187 \mathrm{Y}_{2} \mathrm{Y}_{3}
\end{gathered}
$$

Where $\mathrm{Z}$ is the response variable (percentage removal of copper from wastewater effluent) and $\mathrm{Y}_{1}-\mathrm{Y}_{3}$ are the uncoded values of the independent variables $(\mathrm{pH}$, sorbent dosage, and initial concentration of wastewater effluent spiked with $\mathrm{Cu}(\mathrm{II}))$.

Table 1. CCD Experimental ranges and levels of independent variables

\begin{tabular}{|c|c|c|c|c|c|c|}
\hline $\begin{array}{c}\text { Independent } \\
\text { variable }\end{array}$ & $\begin{array}{c}\text { Factor } \\
\text { code }\end{array}$ & \multicolumn{5}{|c|}{ Range and level } \\
\hline $\mathrm{pH}$ & $\mathrm{Y}_{1}$ & 5.0 & 5.6 & 6.5 & 7.4 & 8.0 \\
\hline $\begin{array}{c}\text { Sorbent dosage } \\
(\mathrm{g} / \mathrm{L})\end{array}$ & $\mathrm{Y}_{2}$ & 0.5 & 2.34 & 5.25 & 8.16 & 10.0 \\
\hline $\begin{array}{c}\text { Initial } \\
\text { concentration of } \\
\text { wastewater } \\
\text { effluent spiked } \\
\text { with Cu(II) } \\
(\mathrm{mg} / \mathrm{L})\end{array}$ & $\mathrm{Y}_{3}$ & 1.00 & 1.78 & 3.00 & 4.23 & 5.00 \\
\hline
\end{tabular}

\subsubsection{Analysis of Variance (ANOVA) Using RSM Model}

Results for the percentage of $\mathrm{Cu}$ (II) removal from wastewater effluent spiked with $\mathrm{Cu}$ (II) were obtained by performing batch experiments according to the CCD matrix of conditions. The experimental results obtained from the various runs, together with the values predicted by the built RSM model, with residual values in the range of 0.21 to 4.8 , which influenced the value of $\mathrm{R}^{2}$.

In order to test the suitability of the model, the predicted and actual experimental values were plotted to provide the coefficient of determination $\left(\mathrm{R}^{2}=0.9409\right)$. The $\mathrm{R}^{2}$ value in this study was low compared to other studies that used a clean water matrix for the adsorption process [23]. For example, the study of a cellulose-based adsorbent for chromium removal from a clean water matrix, for instance, showed a high coefficient of determination $\left(\mathrm{R}^{2}=0.9959\right)$ [24].

Analysis of variance (ANOVA) for $\mathrm{Cu}$ (II) removal from the effluent was applied to evaluate the quality of fit of the model. The significance of each term in the equation to the percentage of the adsorbed $\mathrm{Cu}$ (II) ions was validated by this statistical test. The results of the second-order response surface model fitting in the form of ANOVA are shown in Table 2 .

Generally, it can be considered that higher Fisher's F-test values and lower $P$ values indicate the significance of the coefficients of the parameters. Values of $\mathrm{P}$ that are greater than 0.10 indicate that the model terms are not significant [25]. As seen from Table 2, all the first-order main effects in the quadratic model are statistically significant $(\mathrm{P}<0.05)$ for their effect on the $\mathrm{Cu}(\mathrm{II})$ percentage removal from the effluent. However, the second-order effect of $\mathrm{pH}\left(Y_{1}^{2}\right)$ on the $\mathrm{Cu}$ (II) percentage removal is not significant among the other second-order effects. Meanwhile, other variables such as $\mathrm{Y}_{1} \mathrm{Y}_{2}, \mathrm{Y}_{1} \mathrm{Y}_{3}$, and $\mathrm{Y}_{2} \mathrm{Y}_{3}$ also had non-significant effects on the $\mathrm{Cu}$ (II) percentage removal $(\mathrm{P}>0.10)$. 
Table 2. Analysis of variance (ANOVA) of $\mathrm{Cu}(\mathrm{II})$ removal prediction by using RSM model

\begin{tabular}{|c|c|c|c|c|c|c|}
\hline Source & Sum of squares & DF & Mean square & F-value & $\begin{array}{c}\text { P-value } \\
\text { Prob }>\text { F }\end{array}$ & Co-efficient \\
\hline Model & 1120.08 & 9 & 124.45 & 22.72 & $<0.0001$ & 81.4753 \\
\hline$Y_{1}$ & 33.11 & 1 & 33.11 & 6.05 & 0.036 & 1.5759 \\
\hline$Y_{2}$ & 231.31 & 1 & 231.30 & 42.23 & $<0.0001$ & 4.1651 \\
\hline$Y_{3}$ & 683.31 & 1 & 683.31 & 124.76 & $<0.0001$ & 7.1588 \\
\hline$Y_{1}{ }^{2}$ & 21.18 & 1 & 11.80 & 2.15 & 0.176 & 0.9451 \\
\hline$Y_{2}{ }^{2}$ & 62.59 & 1 & 72.42 & 13.22 & 0.005 & -2.3414 \\
\hline$Y_{3}{ }^{2} Y_{2}$ & 75.11 & 1 & 75.11 & 13.71 & 0.005 & -2.3848 \\
\hline$Y_{1} Y_{3}$ & 0.83 & 1 & 0.83 & 0.15 & 0.707 & -0.3212 \\
\hline$Y_{2} Y_{3}$ & 0.76 & 1 & 0.76 & 0.14 & 0.718 & -0.3087 \\
\hline Residual & 11.88 & 1 & 11.88 & 2.17 & 0.175 & -1.2187 \\
\hline Lack of fit & 49.29 & 9 & 5.447 & & & Significant \\
\hline Pure error & 45.74 & 5 & 9.148 & 10.3 & 0.021 & \\
\hline Total & 3.55 & 4 & 0.888 & & & \\
\hline
\end{tabular}

*DF- degree of freedom

In order to improve the accuracy of the model, the insignificant terms were removed from the quadratic equation. However, there was no improvement to the accuracy of the model, even after eliminating the insignificant terms. The significance of lack of fit indicates that the RSM model is invalid for the present work when it has a value of less than $0.05[26,27]$. Therefore, from the results, the lack of fit obtained is significant due to low probability $(\mathrm{P}=0.005)$ and a higher $\mathrm{F}$-test value of 15.31 , which is reinforced by the relatively low coefficient of determination $\left(\mathrm{R}^{2}=0.9409\right)$ for the overall model. Therefore, this result shows that the RSM model is unable to effectively predict the removal of spiked $\mathrm{Cu}$ (II) from wastewater effluent.

A possible explanation for the poor fit of the quadratic equation in the RSM model is the variability of wastewater composition, which is likely to influence the efficiency of the adsorption process. Similar observations were found in studies on lead removal from industrial sludge leachate using red mud adsorbent, and in the case of solid-phase extraction of gold from industrial wastewater using modified mesoporous silica. They showed that the variability in real wastewater samples cannot be efficiently predicted by the RSM model $[22,28]$.

\subsubsection{Artificial Neural Network (ANN)}

An ANN-based model was also built for predicting the removal of $\mathrm{Cu}(\mathrm{II})$ from the effluent by oxidised CNWs. In a similar way to RSM modelling, the data generated through $\mathrm{CCD}$ were used to determine the optimal architecture of the ANN model. The total of 20 experiments were divided into three subsets comprising training (12 data points), validation (4 data points) and testing (4 data points).

Although ANN and RSM models in combination with experimental design have been increasingly applied in the area of water and wastewater treatment, the operation of a WWTP is often complicated because of the complexity of the wastewater matrix; this varies both temporally and spatially. A study by Ebrahimzadeh et al., (2012) showed good agreement between ANN predictions and experimental data, with a correlation coefficient of 0.9945 , whereas this amount decreases to 0.8857 for an RSM model. However, there was no obvious reported improvement in the determination of metal ions from an industrial sample, even after applying the optimum conditions suggested by both models [28].

Of these two models, ANN is found to be more efficient and more suitable for modelling such WWTP processes due to its accuracy and adequacy, and is promising in engineering applications [20]. ANN is more appropriate in the case of complex processes (i.e. WWTP processes) as the model allows for predictions of the output on the basis of input data without the need to define the relationship between them [20].

A number of high quality reviews have appeared in the literature dealing with the application of ANN-based models in the field of water treatment $[29,30]$. However, no work to date has included the variation in wastewater composition as one of the independent variables (ANN input) for remediation of $\mathrm{Cu}$ (II) from wastewater. For example, a study by Aber et al., (2009) observed that the performance of electrocoagulation processes in removal of $\mathrm{Cr}(\mathrm{VI})$ from synthetic and real wastewater was successfully predicted by an ANN model [31]. Even though this study included effective parameters as independent variables, the process is often complicated due to the variety of contamination present in raw wastewater.

The issue with these studies is the assumption that the actual wastewater composition is the same for each 
experiment, or that its composition has no influence on the removal capability of that process. Therefore, in order to study the effect of variation in wastewater composition through removal of spiked $\mathrm{Cu}$ (II) from wastewater effluent, benchmark experiments were conducted for each sampling trip. The results obtained from the benchmark experiments showed that the percentage removals $(74.41-78.76 \%)$ were different from each sampling trip, due to complexity of the wastewater matrix and its variability. Thus, it can be summarised that the variation of actual wastewater composition affects adsorption performance. The results obtained from benchmark experiments will therefore be included as the fourth independent variable in ANN modelling. The coefficient of determination $\left(\mathrm{R}^{2}=0.9963\right)$ for the ANN model with variability indicates good agreement between experimental and predicted results.

For a better graphical interpretation of the process of $\mathrm{Cu}(\mathrm{II})$ adsorption from wastewater, three-dimensional response surface plots were generated. The mutual interactive behaviour between two in-dependent variables, while the third variable is held constant at its intermediate value ( $\mathrm{pH} 6.5,5.25 \mathrm{~g} / \mathrm{L}, 3 \mathrm{mg} / \mathrm{L})$, is shown in Figure 1 .

As shown in Figure 1(A), maximum removal of $\mathrm{Cu}(\mathrm{II})$ is observed at a sorbent dosage of $8 \mathrm{~g} / \mathrm{L}$ and $\mathrm{pH}$. The percentage $\mathrm{Cu}(\mathrm{II})$ removal increased with the increase of $\mathrm{pH}$ due to the negative surface charge of oxidised $\mathrm{CNW}$ at alkaline $\mathrm{pH}$ values. At $\mathrm{pH} 8$ and above, carboxyl group, $\mathrm{COOH}$, was changed into-COO-, hence the ion exchange between $\mathrm{Cu}(\mathrm{II})$ and potential functional groups increased [12]. The low adsorption that takes place in acidic solutions can be due to the competition between hydrogen and copper ions for active sites on the oxidised CNW surface [32]. However, $\mathrm{pH}$ did not significantly affect the adsorption removal, contrary to the findings of other studies, as the $\mathrm{pH}$ range studied in this work is narrow $\mathrm{pH}$ 5.0-8.0). The effect of $\mathrm{pH}$ on the adsorption of $\mathrm{Cr}(\mathrm{VI})$ was investigated by varying $\mathrm{pH}$ from 2.0 to 10.0 . Due to the wide $\mathrm{pH}$ range, $\mathrm{pH}$ was found to be one of the main parameters affecting the ad-sorption process [33].

Figure 1(B) shows the interaction effect of sorbent dosage and initial concentration of wastewater effluent spiked with $\mathrm{Cu}(\mathrm{II})$ on the removal of $\mathrm{Cu}$ (II) from the effluent, with $\mathrm{pH}$ held constant at $\mathrm{pH}$ 6.5. The $\mathrm{Cu}(\mathrm{II})$ removal increases with increasing sorbent dosage, which may be due to the increase in total surface active sites on the adsorbent surface. The amount of proton exchange between the adsorbent and the solutions increases with increasing sorbent dosage. Similar observations were found in studies on $\mathrm{Cu}(\mathrm{II})$ removal using alkali-modified spent tea, and in the case of $\mathrm{Cr}(\mathrm{VI})$ removal by modified silica [25]. Percentage removal of $\mathrm{Cu}(\mathrm{II})$ increases when $\mathrm{pH}$ and initial concentration of wastewater effluent spiked with $\mathrm{Cu}(\mathrm{II})$ increase, as shown in Figure 1(C). The increasing initial concentration of wastewater effluent spiked with $\mathrm{Cu}$ (II) provides the driving force to overcome the mass transfer resistance of $\mathrm{Cu}(\mathrm{II})$ ions between the aqueous and solid phases. Similar observations were reported in the literature, where the maximum $\mathrm{Cu}(\mathrm{II})$ removal by Trametes versicolor fungi was observed when initial $\mathrm{Cu}$ (II) concentration increased from 37 to $60 \mathrm{mg} / \mathrm{L}$ at $\mathrm{pH}$ of 5.51 [34]. 

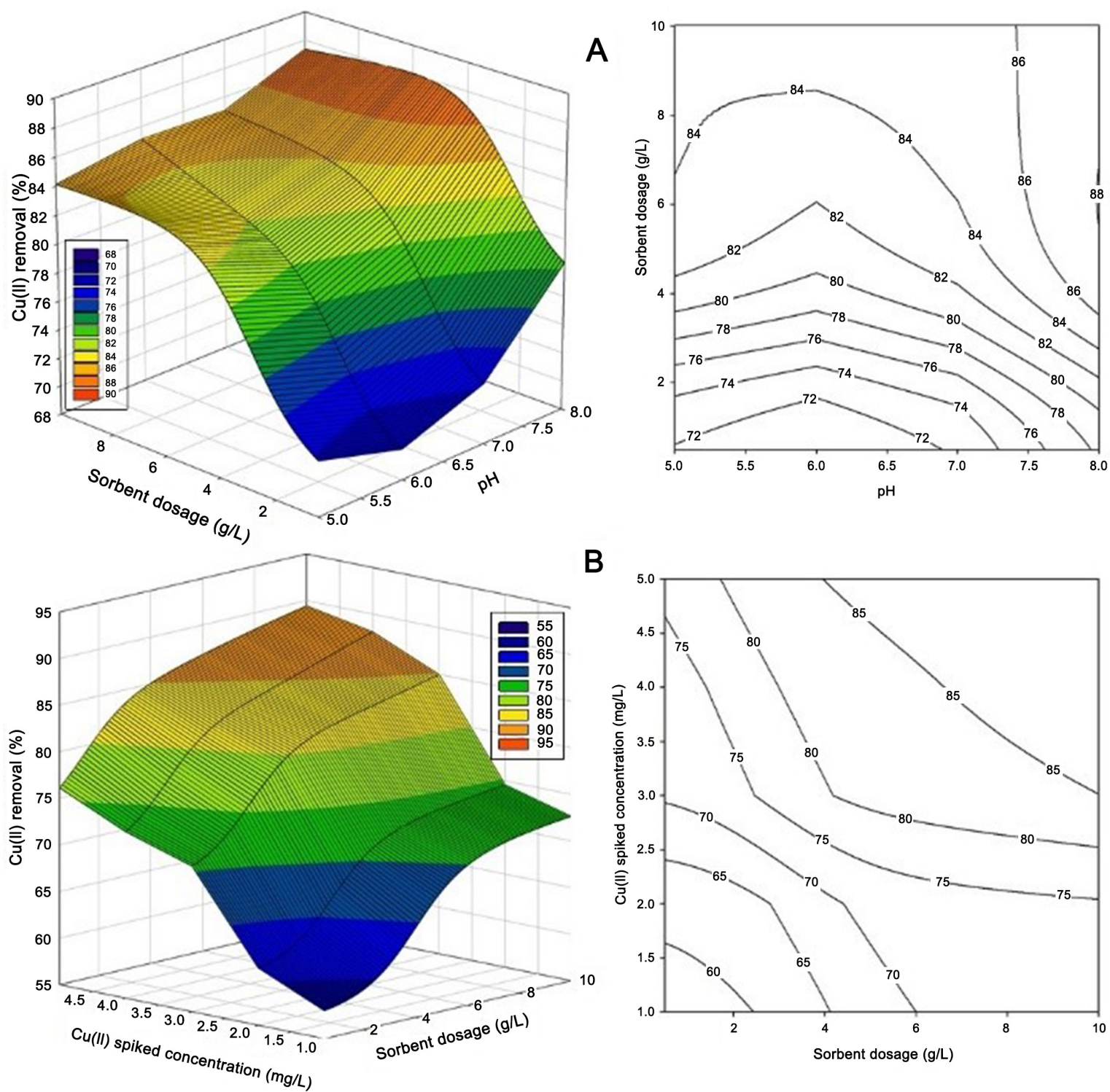

B
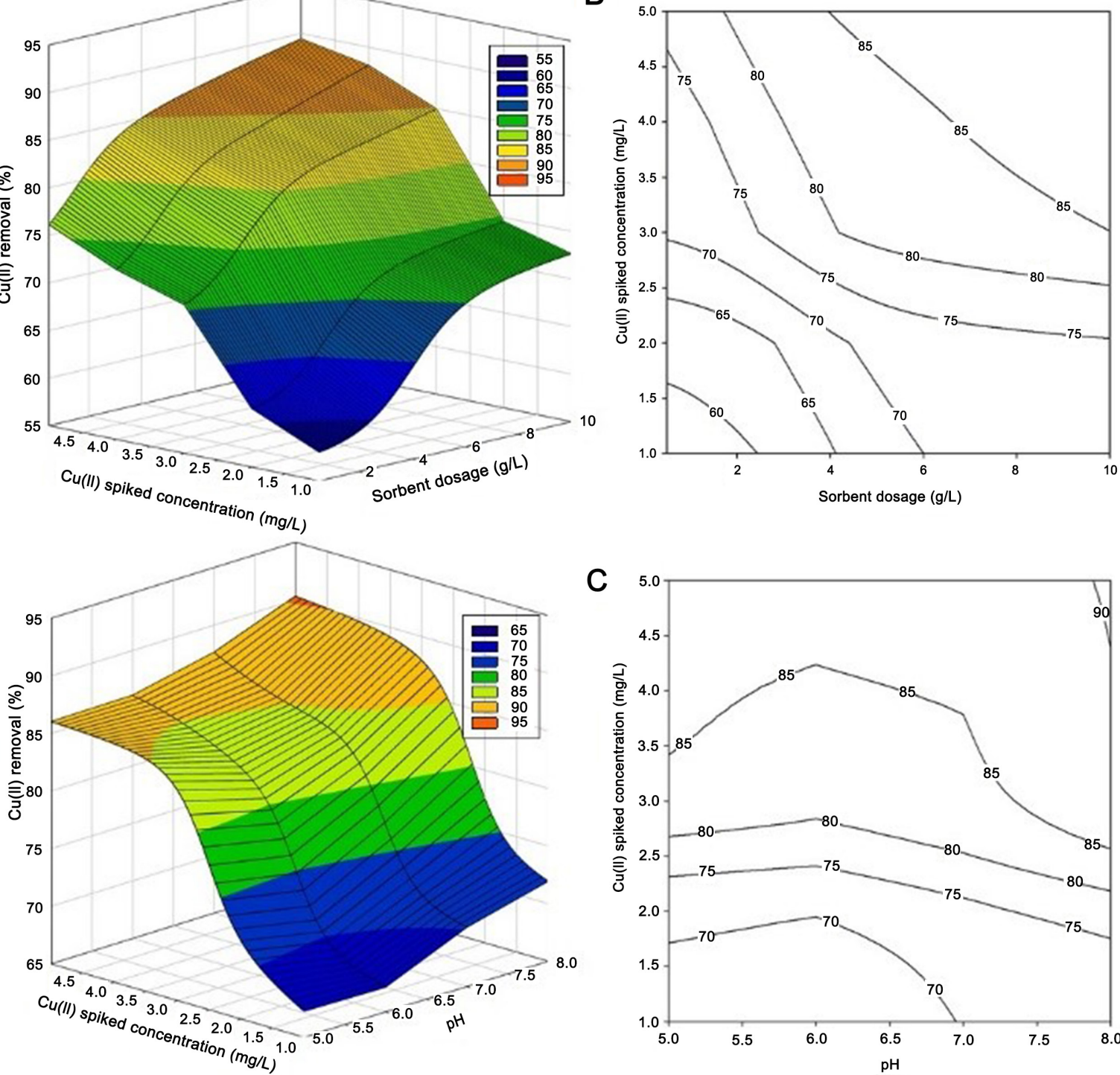

Figure 1. Surface plots (left) and corresponding contour plots (right) showing the effects of adsorption parameters on the spiked Cu (II) removal from wastewater effluent as predicted by the ANN model with initial concentration of wastewater effluent spiked with $\mathrm{Cu}(\mathrm{II})$ held constant $3 \mathrm{mg} / \mathrm{L}$ (A), $\mathrm{pH}$ held constant at 6.5 (B) and sorbent dosage held constant at $5.25 \mathrm{~g} / \mathrm{L}(\mathrm{C})$ 


\subsection{Multiple Linear Regression (MLR)}

Multiple linear regression (MLR) is a linear statistical analysis that is applicable for predicting the relationship between a dependent variable and two or more independent variables [35]. In MLR, the dependent variable is known as the predictand, while the independent variables are the predictors [36]. MLR models are used in the prediction of $\mathrm{Cu}(\mathrm{II})$ removal from the wastewater matrix, being represented by the relationship between the percentage removal and a set of predictor variables. MLR is based on least squares fit, where the model is adjusted so that the sum of squares of differences of actual and predicted values is minimised. The general MLR equation can be formulated by:

$$
\ddot{Y}=\beta_{0}+\beta_{1} X_{1}+\cdots+\beta_{n} X_{n}+\varepsilon
$$

Where $\ddot{Y}$ is the dependent variable, $X_{n}$ the independent variables, $\beta_{\mathrm{n}}$ the predicted parameters, and $\varepsilon$ is the error term.

Multiple linear regression (MLR) and artificial neural networks (ANNs) were used to predict the removal of $\mathrm{Cu}$ (II) from the effluent by oxidised $\mathrm{CNW}$ adsorbents. The data used in the MLR and ANN models were obtained from $20 \mathrm{CCD}$ experiments. The MLR model (with and without accounting for the variability of the wastewater matrix) gives the mathematical expression of the output of the MLR analysis:

$$
\begin{gathered}
\mathrm{Z}(\%)=17.0722+1.7352 \mathrm{Y}_{1}+1.6348 \mathrm{Y}_{2}+5.7487 \mathrm{Y}_{3}+ \\
0.3218 \mathrm{Y}_{4}
\end{gathered}
$$

Where $\mathrm{Z}$ is the dependent variable (percentage removal of copper from wastewater effluent) and $Y_{i}$ the independent variables $(\mathrm{pH}$, sorbent dosage, initial concentration of wastewater effluent spiked with $\mathrm{Cu}(\mathrm{II})$ and benchmark experiment, respectively).

\subsection{Statistical Comparison and Performance of Models for Wastewater Effluent}

The performance of the built MLR and ANN models (with and without accounting for the variability of the wastewater matrix) was compared and statistically measured by the coefficient of determination $\left(\mathrm{R}^{2}\right)$, absolute average deviation (AAD), and root mean squared error (RMSE).

The ANN including variability of wastewater matrix model fitted the experimental data with excellent accuracy and with a better prediction $(\mathrm{R} 2=0.9963)$ than the ANN not including variability $(\mathrm{R} 2=0.9945)$, and than the MLR model including $(\mathrm{R} 2=0.7994)$ and not including variability $(\mathrm{R} 2=0.7961)$. The AAD and RMSE for the ANN model including variability of wastewater matrix were calculated to be $0.30 \%$ and 0.48 respectively, whilst those of the ANN model were $0.63 \%$ and 0.69 respectively.
In addition to the coefficients of determination for ANNs, the AAD and RMSE confirm that the ANN model including the variability of the wastewater matrix as the fourth independent variable is superior in predicting the removal of spiked $\mathrm{Cu}(\mathrm{II})$ from wastewater effluent.

A possible explanation for this result is the complexity of the wastewater in term of composition and its variability, which can affect the capability of the adsorbent to remediate $\mathrm{Cu}$ (II) from the wastewater matrix. A variety of organic and inorganic compounds can be found in the composition of wastewater, and its variability, both temporally and spatially (within a WWTP and in different wastewater streams), is likely to influence the efficiency and capability of oxidised CNW adsorbents. This explanation is stated that in a real WWTP, the water matrix will be far more complex than clean water. Thus, with the results obtained from benchmark experiments, it is demonstrated that the complexity and variability in wastewater composition affect the adsorption performance.

This finding has also been supported by other studies that have not included the variations in real wastewater composition as one of the independent variables (ANN input). For instance, although Geyikci and his co-workers reported that the results of ANN were found to be more reliable than RSM $\left(\mathrm{R}^{2}=0.672\right)$, a low coefficient of determination $\left(\mathrm{R}^{2}=0.898\right)$ from the ANN model indicated that the variation in industrial sludge leachate composition had an influence on the removal capability of the adsorbent. The major issue with this study is the assumption that real wastewater composition is the same for each sample, or has no impact on the removal capability of the adsorbent. Hence, it can be concluded that including wastewater variability as one of the input variables will lead to improvements in the predictability of the ANN model.

\subsubsection{Model Validation Using Unseen Experiments}

For validation, additional 10 unseen experiments were conducted, consisting of combinations of experimental factors that were not considered in the $20 \mathrm{CCD}$ experiments. This was a necessary procedure, since no work has been reported to date in the choice of additional experiments to represent the whole system of remediating $\mathrm{Cu}$ (II) from a wastewater matrix. 3D scatter plots for the unseen experiments are displayed in Figure 2, and include a comparison of 3D scatter plots derived from data contained in two other studies which involved real wastewater samples. The 10 unseen experiments undertaken in this study, illustrated in Figure 2(A), were chosen to represent parameter space both inside and outside the system, to better understand and test the validity of the models.

However, as illustrated in Figure 2(B), Ebrahimzadeh et al., (2012) designed 10 random experiments, using MATLAB programming, which did not represent the whole system, in order to study the predictability of the RSM and ANN models for solid-phase extraction of gold ions from industrial wastewater [28]. Furthermore, in order 
to test the validity of RSM and ANN results, Geyikci et al., concentrated inside the system, as shown in Figure 2(C) (2012) conducted 10 extra experiments that were all [22].
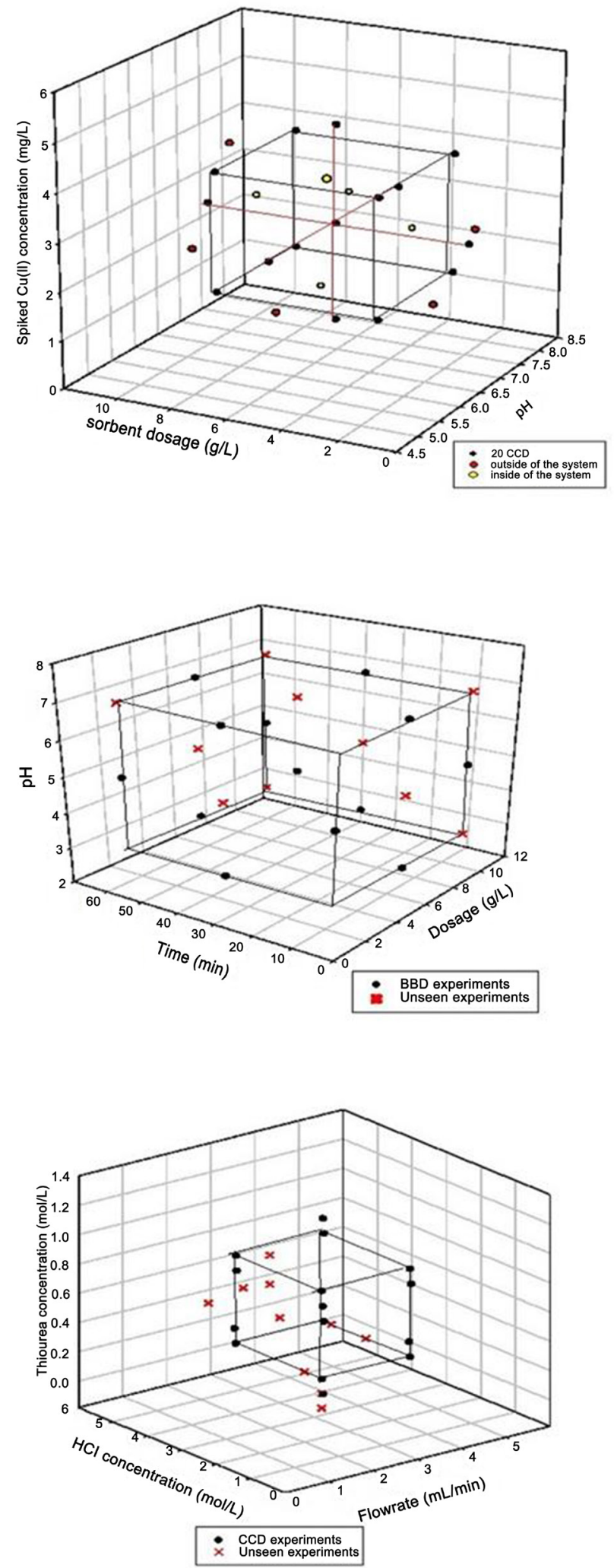

Figure 2. 3D scatter plots showing: (A) comparison of the CCD with unseen experiments within the systems for this work; (B) solid-phase extraction for determination of gold from industrial wastewater [28]; (C) Lead adsorption from industrial sludge leachate [22] 
Table 3. Validation data for 10 unseen experiments

\begin{tabular}{|c|c|c|c|c|c|c|c|c|c|c|c|c|c|c|}
\hline \multirow{3}{*}{ Data index } & \multirow{3}{*}{ Run } & \multicolumn{4}{|c|}{ Inputs } & \multicolumn{9}{|c|}{$\mathrm{Cu}(\mathrm{II})$ removal (\%) } \\
\hline & & \multirow{2}{*}{$\mathrm{Y}_{1}$} & \multirow{2}{*}{$\mathrm{Y}_{2}$} & \multirow{2}{*}{$\mathrm{Y}_{3}$} & \multirow{2}{*}{ Benchmarks (\%) } & \multirow{2}{*}{ Actual } & \multicolumn{2}{|c|}{ MLR } & \multicolumn{2}{|c|}{$\begin{array}{c}\text { MLR } \\
\text { (WW variation) }\end{array}$} & \multicolumn{2}{|c|}{ ANN } & \multicolumn{2}{|c|}{$\begin{array}{c}\text { ANN } \\
\text { (WW variability) } \\
\end{array}$} \\
\hline & & & & & & & Predicted & Residual & Predicted & Residual & Predicted & Residual & Predicted & Residual \\
\hline \multirow{5}{*}{ Outside of the system } & 1 & 7 & 1 & 3 & 71.96 & 74.49 & 73.53 & -0.96 & 71.26 & -3.23 & 72.98 & 1.51 & 77.61 & -3.12 \\
\hline & 2 & 6 & 1 & 2 & 71.96 & 65.81 & 65.95 & 0.14 & 63.77 & -2.04 & 60.68 & 5.13 & 64.98 & 0.83 \\
\hline & 3 & 5 & 8 & 3 & 77.39 & 76.88 & 80.08 & 3.20 & 77.52 & 0.64 & 84.14 & -7.26 & 81.92 & -5.04 \\
\hline & 4 & 7 & 10 & 4 & 77.39 & 78.72 & 92.26 & 13.54 & 90.01 & 11.29 & 87.54 & -8.82 & 86.28 & -7.56 \\
\hline & 5 & 5 & 5 & 2 & 78.76 & 68.8 & 69.94 & 1.14 & 67.41 & -1.39 & 71.25 & -2.45 & 72.81 & -4.01 \\
\hline \multirow{5}{*}{ Inside of the system } & 6 & 6 & 4 & 4 & 78.76 & 77.64 & 71.67 & -4.72 & 70.04 & -6.35 & 69.93 & 6.46 & 74.31 & 2.08 \\
\hline & 7 & 6 & 5 & 2 & 74.41 & 72.50 & 83.99 & 6.09 & 81.91 & 4.01 & 84.92 & -7.02 & 77.07 & 0.83 \\
\hline & 8 & 5.5 & 4 & 4.5 & 74.41 & 77.9 & 75.77 & 1.38 & 74.15 & -0.24 & 80.19 & -5.80 & 80.01 & -5.62 \\
\hline & 9 & 7.5 & 4 & 2.5 & 78.76 & 74.39 & 84.98 & 6.05 & 82.62 & 3.69 & 84.85 & -5.92 & 86.01 & -7.08 \\
\hline & 10 & 7 & 9 & 3 & 74.15 & 78.93 & 79.82 & 1.36 & 77.39 & -1.07 & 82.29 & -3.83 & 82.04 & -3.58 \\
\hline
\end{tabular}

$\mathrm{Y}_{1}=\mathrm{pH} ; \mathrm{Y}_{2}=$ sorbent dosage; $\mathrm{Y}_{3}=$ initial concentration of wastewater effluent spiked with $\mathrm{Cu}(\mathrm{II}) ; \mathrm{WW}=$ wastewater

Table 4. Comparison of the predictive abilities of RSM and ANN model

\begin{tabular}{|c|c|c|c|c|c|c|c|c|}
\hline \multirow[b]{2}{*}{ Data index } & \multicolumn{4}{|c|}{$\mathrm{AAD}(\%)$} & \multicolumn{4}{|c|}{ RMSE } \\
\hline & MLR & $\begin{array}{c}\text { MLR } \\
\text { (WW variability) }\end{array}$ & ANN & $\begin{array}{c}\text { ANN } \\
\text { (WW variability) }\end{array}$ & MLR & $\begin{array}{c}\text { MLR } \\
\text { (WW variability) }\end{array}$ & ANN & $\begin{array}{c}\text { ANN } \\
\text { (WW variability) }\end{array}$ \\
\hline $20 \mathrm{CCD}$ & 3.23 & 3.84 & 0.63 & 0.30 & 3.48 & 3.46 & 0.69 & 0.48 \\
\hline 10 unseen & 4.98 & 4.38 & 7.17 & 5.23 & 5.43 & 4.64 & 5.83 & 4.57 \\
\hline 5 Inside & 5.05 & 3.84 & 7.53 & 4.98 & 4.46 & 4.46 & 5.90 & 4.46 \\
\hline 5 Outside & 4.90 & 4.93 & 6.81 & 5.49 & 6.26 & 5.37 & 5.75 & 4.67 \\
\hline
\end{tabular}

$\mathrm{AAD}=$ absolute average deviation; $\mathrm{RMSE}=$ root mean squared error; $\mathrm{WW}=$ wastewater 
The actual and predicted values of the responses for the 10 unseen experiments, along with their residual values for the models, are summarised in Table 3. Moreover, the $\mathrm{R}^{2}$ for both models $\left(\mathrm{R}^{2}=0.9644\right.$ for $\mathrm{ANN}$ including wastewater variability, $\mathrm{R}^{2}=0.8991$ for ANN without), show that the ANN model predicts more accurately when variation in wastewater composition is included as the fourth independent variable. As shown in Table 4, the predictive abilities of the newly constructed MLR and ANN models, with and without wastewater variability, were statistically measured in terms of $\mathrm{R}^{2}, \mathrm{AAD}$ and RMSE. From the results, it is confirmed that the ANN model including wastewater variability predicts more accurately the remediation of spiked $\mathrm{Cu}$ (II) from wastewater effluent, in both the original $20 \mathrm{CCD}$ and the 10 unseen experiments. This is because the ANN model allows for predicting the response (percentage of $\mathrm{Cu}(\mathrm{II})$ removal) without the need to justify the relationship between them, which is particularly important in the case of real-world WWTP, where the water matrix will be more complex [20].

This finding has also been supported by others who have used MLR and ANN in prediction studies. For instance, Tiryaki and his co-workers used ANN and MLR for predicting the compression strength of heat-treated woods. The results indicated that an ANN model provided better prediction results compared to an MLR model. Moreover, ANN models save time and decrease the experimental costs [35]. Another advantage of the ANN model is the flexibility to work with more input variables, which is helpful when involving large number of experiments; for MLR, a large number of input variables lead to a polynomial with many coefficients that involve tedious computation [36].

\section{Conclusions}

Oxidised CNW adsorbents are capable of removing spiked $\mathrm{Cu}(\mathrm{II})$ ions from wastewater effluent. The RSM and ANN models were employed to optimise the system and to create a good predictive model. No work in the reviewed literature included matrix complexity and the variability of the wastewater as one of the independent variables in ANN modelling. Evidently this novel approach and the outcomes were employed in this study for the first time, as most studies do not consider matrix variability and its impact when evaluating the efficiency of an adsorbent. To test the predictive capability of these models, additional 10 unseen experiments, not used in developing both models, were chosen to represent the system of conditions both inside and outside the system. This study (20 CCD and 10 unseen experiments) found that the ANN model accounting for wastewater variability was superior to the RSM model and to the ANN model not including wastewater variability, in terms of the coefficient of determination $\left(\mathrm{R}^{2}\right)$, the absolute average deviation (AAD) and root mean squared error
(RMSE) when predicting the efficiency of $\mathrm{Cu}(\mathrm{II})$ removal from the wastewater matrix. The optimum adsorption conditions were determined as an initial $\mathrm{pH}$ value of 8.0 , a sorbent dosage of $6.45 \mathrm{~g} / \mathrm{L}$ and initial $\mathrm{Cu}(\mathrm{II})$ concentration of $4.72 \mathrm{mg} / \mathrm{L}$. At optimum adsorption conditions, the percentage removal of spiked $\mathrm{Cu}(\mathrm{II})$ from the wastewater effluent was found to be $92.11 \%$. Although oxidised CNW adsorbents were able to remove approximately $90 \%$ of spiked $\mathrm{Cu}(\mathrm{II})$ from wastewater effluent, the physical structure of oxidised CNW adsorbents are not suitable for use in continuous flow column operations.

\section{Acknowledgements}

The author (Hazren Hamid) would like to acknowledge the support from University of Tun Hussein Onn Malaysia (UTHM) for financial support under Grant Tier 1 (Code Grant: H200) and Government of Malaysia for a scholarship from the Majlis Amanah Rakyat (MARA).

\section{REFERENCES}

[1] Hanafiah, M.A.K.M., et al., Enhanced adsorption of $\mathrm{Pb}(\mathrm{II})$ on chemically treated neem (Azadirachta indica) leaf powder, in Material Science and Engineering Technology Ii, K.M. Gupta, Editor. 2014. p. 128-133.

[2] Ileri, O., et al., Removal of common heavy metals from aque-ous solutions by waste salvadora persica L. Branches (Mi-swak). International Journal of Environmental Research, 2014. 8(4): p. 987-996.

[3] Turan, N.G., B. Mesci, and O. Ozgonenel, Response surface modeling of $\mathrm{Cu}(\mathrm{II})$ removal from electroplating waste by ad-sorption: application of BoxBehnken experimental design. Clean-Soil Air Water, 2013. 41(3): p. 304-312.

[4] Bingol, D., et al., Comparison of the results of response sur-face methodology and artificial neural network for the bio-sorption of lead using black cumin. Bioresource Technology, 2012. 112: p. 111-115.

[5] Shanmugaprakash, M. and V. Sivakumar, Development of experimental design approach and ANN-based models for de-termination of $\mathrm{Cr}(\mathrm{VI})$ ions uptake rate from aqueous solution onto the solid biodiesel waste residue. Bioresource Technolo-gy, 2013. 148: p. 550-559.

[6] Li, L., et al., Optimization of methyl orange removal from aqueous solution by response surface methodology using spent tea leaves as adsorbent. Frontiers of Environmental Sci-ence \& Engineering, 2014. 8(4): p. 496-502.

[7] Mandal, S., et al., Artificial neural network modelling of As(III) removal from water by novel hybrid material. Process Safety and Environmental Protection, 2015. 93: p. 249-264.

[8] CEC, Council directive on pollution caused by certain danger-ous substances discharged into the aquatic 
environment of the Community. 1976, Council of the European Communities.

[9] CEC, Directive 2000/60/EC of the European Parliament and of the Council on establishing a framework for Community ac-tion in the field of water policy. 2000, Council of the Europe-an Communities.

[10] Isobe, N., et al., TEMPO-oxidized cellulose hydrogel as a high-capacity and reusable heavy metal ion adsorbent. Journal of hazardous materials, 2013. 260: p. 195-201.

[11] Alves, G., V. Leandro, and L.F. Gil, Adsorption of $\mathrm{Cu}(\mathrm{II})$, $\mathrm{Cd}(\mathrm{II})$, and $\mathrm{Pb}(\mathrm{II})$ from aqueous single metal solutions by succinylated mercerized cellulose modified with triethylenetet-ramine. Carbohydrate Polymers, 2009. 77(1): p. 142-149.

[12] Reddy, D.H.K., Seshaiah, K.,Reddy, A. V. R.,Lee, S. M., Op-timization of $\mathrm{Cd}(\mathrm{II}), \mathrm{Cu}(\mathrm{II})$ and $\mathrm{Ni}(\mathrm{II})$ biosorption by chemi-cally modified moringa oleifera leaves powder. Carbohydrate Polymers, 2012. 88(3): p. 1077-1086.

[13] Eyley, S. and W. Thielemans, Surface modification of cellu-lose nanocrystals. Nanoscale, 2014. 6(14): p. 7764-7779.

[14] Saito, T., et al., Distribution of carboxylate groups introduced into cotton linters by the TEMPO-mediated oxidation. Carbo-hydrate Polymers, 2005. 61(4): p. 414-419.

[15] Ghosh, A., P. Das, and K. Sinha, Modeling of biosorption of $\mathrm{Cu}$ (II) by alkali-modified spent tea leaves using response sur-face methodology (RSM) and artificial neural network (ANN). Applied Water Science, 2015. 5(2): p. 191-199.

[16] Labet, M. and W. Thielemans, Improving the reproducibility of chemical reactions on the surface of cellulose nanocrystals: ROP of epsilon-caprolactone as a case study. Cellulose, 2011. 18(3): p. 607-617.

[17] Habibi, Y., H. Chanzy, and M.R. Vignon, TEMPO-mediated surface oxidation of cellulose whiskers. Cellulose, 2006. 13(6): p. 679-687.

[18] APHA, Standard Methods for the Examination of Water and Wastewater. 1998, American Public Health Association: American Public Health Association: Washington, D.C.

[19] Ghosh, A., K. Sinha, and P. Das Saha, Central composite de-sign optimization and artificial neural network modeling of copper removal by chemically modified orange peel. Desali-nation and Water Treatment, 2013. 51(40-42): p. 7791-7799.

[20] Witek-Krowiak, A., et al., Application of response surface methodology and artificial neural network methods in model-ling and optimization of biosorption process. Bioresource Technology, 2014. 160: p. 150-160.

[21] Pilkington, J.L., C. Preston, and R.L. Gomes, Comparison of response surface methodology (RSM) and artificial neural networks (ANN) towards efficient extraction of artemisinin from Artemisia annua. Industrial Crops and Products, 2014. 58: p. 15-24.
[22] Geyikci, F., et al., Modelling of lead adsorption from industri-al sludge leachate on red mud by using RSM and ANN. Chem-ical Engineering Journal, 2012. 183: p. 53-59.

[23] Hamid, H.A., et al., Predicting the capability of carboxylated cellulose nanowhiskers for the remediation of copper from water using response surface methodology (RSM) and artifi-cial neural network (ANN) models. Industrial Crops and Products.

[24] Liu, J., et al., Study of glutamate-modified cellulose beads for $\mathrm{Cr}$ (III) adsorption by response surface methodology. Indus-trial \& Engineering Chemistry Research, 2011. 50(18): p. 10784-10791.

[25] Cao, J., et al., Response surface methodology approach for optimization of the removal of chromium(VI) by NH2-MCM-41. Journal of the Taiwan Institute of Chemical Engineers, 2014. 45(3): p. 860-868.

[26] Zulkali, M.M.D., A.L. Ahmad, and N.H. Norulakmal, Oryza sativa L. husk as heavy metal adsorbent: optimization with lead as model solution. Bioresource Technology, 2006. 97(1): p. 21-25.

[27] Hamsaveni, D.R., S.G. Prapulla, and S. Divakar, Response surface methodological approach for the synthesis of isobutyl isobutyrate. Process Biochemistry, 2001. 36(11): p. 1103-1109.

[28] Ebrahimzadeh, H., et al., Optimization of solid-phase extrac-tion using artificial neural networks and response surface methodology in combination with experimental design for de-termination of gold by atomic absorption spectrometry in in-dustrial wastewater samples. Talanta, 2012. 97: p. 211-217.

[29] Hamed, M.M., M.G. Khalafallah, and E.A. Hassanien, Predic-tion of wastewater treatment plant performance using artificial neural networks. Environmental Modelling \& Software, 2004. 19(10): p. 919-928.

[30] Antonopoulou, M., V. Papadopoulos, and I. Konstantinou, Photocatalytic oxidation of treated municipal wastewaters for the removal of phenolic compounds: optimization and model-ing using response surface methodology (RSM) and artificial neural networks (ANNs). Journal of Chemical Technology \& Biotechnology, 2012. 87(10): p. 1385-1395.

[31] Aber, S., A.R. Amani-Ghadim, and V. Mirzajani, Removal of $\mathrm{Cr}(\mathrm{VI})$ from polluted solutions by electrocoagulation: model-ing of experimental results using artificial neural network. Journal of Hazardous materials, 2009. 171(1-3): p. $484-490$.

[32] Rajemahadik, C.F., S.V. Kulkarni, and D.G.S. Kulkarni, Effi-cient removal of heavy metals from electroplating wastewater using electrocoagulation. International Journal of Scientific and Research Publications, 2013. 3(10).

[33] Mohan, S., et al., Synthesis of $\mathrm{CuO}$ nanoparticles through green route using citrus limon juice and its application as na-nosorbent for $\mathrm{Cr}(\mathrm{VI})$ remediation: process optimization with RSM and ANN-GA based model. Process Safety and Envi-ronmental Protection, 2015. 96: p. 156-166. 
[34] Sahan, T., et al., Optimization of removal conditions of cop-per ions from aqueous solutions by Trametes versicolor. Bio-resource Technology, 2010. 101(12): p. 4520-4526.

[35] Tiryaki, S. and A. Aydın, An artificial neural network model for predicting compression strength of heat treated woods and comparison with a multiple linear regression model. Construc-tion and Building Materials, 2014. 62: p. 102-108.

[36] Arulsudar, N., N. Subramanian, and R.S.R. Muthy, Compari-son of Artificial Neural Network and Multiple Linear Regres-sion in the Optimization of Formulation Parameters of Leuprolide Acetate Loaded Liposomes. Journal of Pharmacy and Pharmaceutical Sciences, 2005. 8(2): p. 243-258. 